\title{
A Model of Measuring and Predicting the Water Condition
}

\author{
Yannan Sun \\ North China Electric Power University, Baoding, Hebei, China \\ 1414966613@qq.com
}

\begin{abstract}
Keywords: Water shortage; Intervention plan; Grey predict model; People logistic model; Auto regressive model
\end{abstract}

\begin{abstract}
In this article, we mainly discuss the problem of water shortage and exhaustion and how to relieve it. A model is developed to measure and predict the water condition of a region and then an intervention plan is designed for the water scarcity region.

Firstly, to build the model to measure the water supply ability of a region, "water supply capacity" is defined as the ratio of the total amount of water required to the amount of available water. We use Grey Predict Model, People Logistic Model, Auto Regressive Model and Cubic Spline Interpolation fitting method to predict the "water supply capacity". Then we take Tianjin for example, the model result shows that the water supply ability of it is very poor, which agrees well with the reality.

Secondly, we select the North China as study object where water overloaded in the given UN water scarcity map. After reading a large amount of relevant references, we give an opinion on why and how water is scarce in this region. Moreover, we use the above model to predict the water condition of North China in 15 years. We get that the amount of water required is stable while the amount of available water to be reduced. Thus water scarcity will more severe at the future.

Thirdly, to fix the problem of water shortage, we design an intervention water saving plan. From the solving of the above model, we draw a conclusion that live water consumption and agricultural water consumption account for a large proportion. We apply Ramsey Pricing model to make optimal water price. And we change the way of irrigation from flood irrigation to sprinkling irrigation.
\end{abstract}

Furthermore, according to the prediction, the water consumption is about 34.18123 billion cubic meters in 2137 . But the total water resources predicted is 34.16923 billion cubic meters.

\section{Introduction}

As is known to all, water is the source of life. Thus the discussion on water has been continuously. We know that despite the fact that seventy percent of the earth's surface is covered with water, only a little part of it is fresh. The deep groundwater and ice solid water are difficult to explore with the limitation of technology. However, with the expansion of the population and development of the economy, the demand of clean water has increased rapidly (twice the rate of population). This type of scarcity is called Physical scarcity (the water in some regions cannot meet the need) .Physical scarcity and economic scarcity are two primary causes. In the developing country, there are about 1 billion people have no access to clean water and1.7 billion people have no good sanitation facilities. About 25 million people die from drinking unclear water each year. United Nations estimates that nearly half of the world's population will live in areas lacking water in 2025[1].The lack of sanitation facilities is one of economic scarcity, for example. Meanwhile, water pollution also contributes to the shortage.[2]

Will the clean water be used up someday? How to improve the severe situation by taking measures? To answer these questions, we manage to finish the following work:

- Develop a model to measure the water supply capacity of one region.

- Elaborate the present situation of water shortage and explains the reason of the shortage in a water overloaded area from the Physical and Economical scarcity aspects.

- Use the above model to predict the water situation of the picked region in 15 years and 
illustrate the impact on people.

- Make an Intervention plan for the picked region and analyze its effect.

\section{The Capacity Model}

The Model. To quantify and measure the water supply ability, we firstly put forward a concept"water supply capacity". We mark it as 'A', and "water needed" as 'N', "water provided" as 'P'. Then we get that

$$
A=N / P
$$

The $\mathrm{P}$ is available water in the region for exploiting and utilizing without destroying the environment.

There we assume a standard for us to judge the ability of water supply according to the result A.

Table1 Threshold about the capacity of water supply

\begin{tabular}{cc}
\hline The range of A & The ability of water supply \\
\hline $0 \sim 0.4$ & strong \\
$0.4 \sim 0.7$ & meet the demand well \\
$0.7 \sim 1$ & Meet the demand barely \\
Over 1 & Difficult to Meet the demand \\
difficulty
\end{tabular}

Therefore, to get the result of A, we need to know the numerical value of ' $N$ ' and ' $\mathrm{P}$ ' .

We divide $\mathrm{N}$ into four parts, that is water demand in household, industrial water, agricultural water and water used in other aspects. We describe it with the below equation.

$\mathrm{N}=\mathrm{N} 1+\mathrm{N} 2+\mathrm{N} 3+\mathrm{N} 4$

N1 stands for live water consumption

N2 stands for industrial water consumption;

N3 stands for agricultural water consumption;

N4 stands for water used in other aspects;

Then, each part will be elaborated in this paper.

\section{Consumption Of Water}

Live Water Consumption. Because the population of a region is dynamic, leading to the fact that water consumption is not a constant. After analyzing the calculation steps of the live water consumption, we realize that the water consumption per capita and the population can be predicted with mathematical method. And their product is the amount of water demand in households.

We define water consumption per capita as $N_{l x}$ and the population as $N_{l y}$. So we get that

$$
N 1=N_{1 x} \bullet N_{1 y}
$$

We employ the Grey Verhulst Prediction model to get the water consumption per capita of region.

The Grey Model. [3]Firstly, we use the date in previous years to get an original sequence. Assume there are 10 numbers.

$$
X(0)=(x(0)(1), x(0)(2), x(0)(3), \cdots, x(0)(10))
$$


Accumulate once

$X(1)=(x(1)(1), x(1)(2), x(1)(3), \cdots, x(1)(10))$

The mean generation sequence

$\mathrm{Z}(1)=(\mathrm{z}(1)(2), \mathrm{z}(1)(3), \cdots, \mathrm{z}(1)(10))$

Then

$\mathrm{B}=\left(\begin{array}{ll}-Z^{(1)}(2) & \left(Z^{(1)}(2)\right)^{2} \\ \mathrm{M} & \mathrm{M} \\ -Z^{(1)}(10) & \left(Z^{(1)}(10)\right)^{2}\end{array}\right), \mathrm{Y}=\left(\begin{array}{l}x^{(0)}(2) \\ x^{(0)}(3) \\ \mathrm{M} \\ x^{(0)}(10)\end{array}\right)$.

Least square estimation

$\mathrm{u}=(\mathrm{BTB})-1 \mathrm{BTY}$

Verhulst model

$\frac{d x^{(1)}}{d t}+a x^{(1)}=b\left(x^{(1)}\right)^{2}$

Time response

$\hat{x}_{k+1}^{(1)}=\frac{\hat{a} x^{(0)}(1)}{\hat{b} b x^{(0)}(1)+\left[\hat{a}-\hat{b} x^{(0)}(1)\right] e^{\hat{a} k}}$

$\mathrm{K}=0,1, \cdots, 9$, get the prediction.

People Logistic Model. As for to predict the population, we use the People Logistic Model.

The $\mathrm{x}(\mathrm{t})$ is the population in $\mathrm{t}$ year. Assume the population growth rate $\mathrm{r}(\mathrm{t})$ is a linear function of $\mathrm{x}$.

$r(x)=r-s x$

$\mathrm{xm}$ is the largest population that the natural resource and environment conditions can accommodate. In other word, when $x=x_{m}$

$r\left(x_{m}\right)=0$

So

$r(x)=r\left(1-\frac{x}{x_{m}}\right)$

Develop the Logistic model 


$$
\begin{aligned}
& \frac{d x}{d t}=r\left(1-\frac{x}{x_{m}}\right) x \\
& x\left(t_{0}\right)=x_{0}
\end{aligned}
$$

Its solution

$$
x(t)=\frac{x_{m}}{1+\left(\frac{x_{m}}{x_{0}}-1\right) e^{-r\left(t-t_{0}\right)}}
$$

Estimate the parameter $r$ and $x m$ using MATLAB.[3]

The predict result is as follows:

Table 2 Predicted result of population

\begin{tabular}{ccccc}
\hline Year & Actual data & Predicted data & $\begin{array}{c}\text { Residual } \\
\text { Error }\end{array}$ & $\begin{array}{c}\text { Relative } \\
\text { Error }\end{array}$ \\
\hline 2006 & 1075 & 1075 & 0 & 0 \\
2007 & 1115 & 1130.012 & -15.0124 & 0.013285 \\
2008 & 1176 & 1184.733 & -8.73277 & 0.007371 \\
2009 & 1228 & 1238.879 & -10.8794 & 0.008782 \\
2010 & 1299 & 1292.182 & 6.817751 & 0.005276 \\
2011 & 1355 & 1344.389 & 10.61145 & 0.007893 \\
2012 & 1413 & 1395.267 & 17.73313 & 0.012759 \\
2013 & 1472 & 144.611 & 27.38904 & 0.018959 \\
\hline
\end{tabular}

Industrial Water. There are many uncertain factors in the development of industry. Such as the increase or decrease in factory's amount, the expansion of factory and so on. All these factors will infect the water consumption inevitably. At the last part, we have already talked about the live water consumption, in which water consumption per capita is mentioned. Then we make the ratio of the total amount of water used in industry and the total GDP of region's industry as a variable N2x similarly. In case that there is some relationship between the water consumption and GDP, our simplify is reasonable. Then we mark the total GDP as a variable N2y.

$$
N 2=N_{2 x} \bullet N_{2 y}
$$

To predict N2x, we use the Grey Predict Model again. The follow figure shows predicted data of water consumption/GDP. 


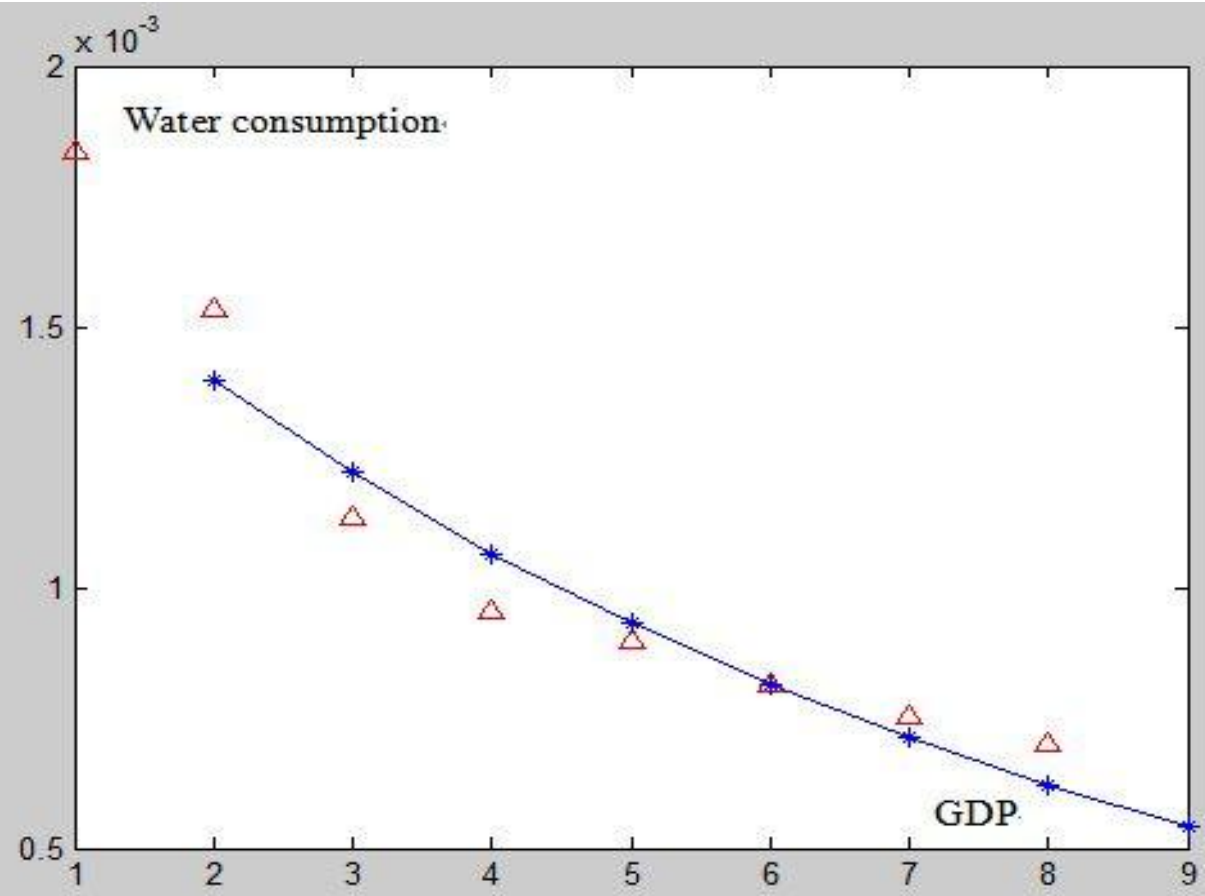

Figure 1. Water consumption per GDP

Meanwhile, we apply the AR model to predict N2y.

Due to the impact of uncertain factors such as the macroeconomic policy and market demand, the forecast of economic operation will meet many difficulties. In the process of economic forecasting, the AR auto regression model not only takes the dependence of economic phenomena on time series into account, but also considers the interference of random fluctuations. Thus the forecast accuracy of the short-term trend of economic operation is higher. So we apply it in to our paper.

The model result is as follows:

Table 3 The result of total GDP

\begin{tabular}{cccc}
\hline Year & Actual data & Predicted data & $\begin{array}{c}\text { Relative } \\
\text { Error }\end{array}$ \\
\hline 2006 & 2457.8 & 2457.8 & 0 \\
2007 & 2892.53 & 2892.53 & 0 \\
2008 & 3709.78 & 3709.78 & 0 \\
2009 & 3987.84 & 4303.549 & 0.079168 \\
2010 & 4840.23 & 4442.268 & 0.08222 \\
2011 & 5928.32 & 5393.401 & 0.090231 \\
2012 & 6663.82 & 6822.035 & 0.023742 \\
2013 & 7275.45 & 7460.972 & 0.0255
\end{tabular}


Agricultural Water. By analyzing the data in previous years, we find that agricultural water has obvious irregularity and concentration. We use the previous data and the Cubic Spline Interpolation fitting method to predict it.[4]

Water Used in Other Aspects. Apart from the above three aspects of water consumption, the region's water supply also has other whereabouts. These should depend on the year's situation. We use the $\varepsilon$ to represent. And $\mathcal{E}$ ' range is \pm 5 billion cubic meters.

\section{Water Supply}

We apply the following expression to calculate the water that a region can provide.

$$
P=\sum_{i} \omega_{i} \bullet \alpha_{i}(A=N / P)
$$

$\omega_{i}=$ the type of water resources that can be exploited.

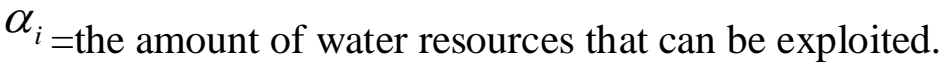

\section{Model Solution and Testing}

Take the Tianjin for example.

We get the predict data of the total amount of water required is 2.348 billion cubic meters in 2014. And the actual data is 2.409 billion cubic meters.

We get the predict data of the total amount of available water is 1.126 billion cubic meters in 2014. And the actual data is 1.137 billion cubic meters

So

\section{$A \approx 2.085$}

The reality of Tianjin is severe water shortage. we have been able to see that the prediction test of our model coincides fairly well with the fact.

The scarcity in North China

Water is source of life and indispensable and irreplaceable natural resources for mankind in its survival and progress. But we can see there are a lot of countries and regions where water is heavily or moderately overloaded. We take the North China for an example to talk about this problem.

North China is China's political, economic and cultural center, but its shortage of water resources is also very serious, the contradiction between supply and demand is very prominent.

Present Situation of Water in North China. Water consumption per capita in china is far below the average level in the world. North China's average amount of area water resources per capita has been about 335 cubic meters for many years, only the 15 percent of the whole country. North China five provinces (municipalities) population accounted for $24.8 \%$, arable land accounts for $45 \%$ of the whole country. Industrial base in the industrial output value accounted for 10 percent of the country's total industrial output value, and the total amount of water resources accounted for only $6 \%$ of the country, per capita water resources, water and land resources allocation proportion were considerably lower than the national average level.[5]

\section{The Reasons Lead to the Water Scarcity}

Physical Scarcity. The temporal and spatial distribution of water resources is the main cause of water resources scarcity in North China.

As we can see from the above form, the water distribution between the north and south is not even. The amount of water in south is far more than north.

Over exploitation of underground water made a funnel structure formed, which promotes the deterioration of the ecological environment. 
Groundwater exploitation in North China is serious, and forms a shallow groundwater funnel area in Beijing, Shijiazhuang, Baoding, Xingtai and Handan, with a total area of over 41 thousand $\mathrm{km} 2$. Besides, in some cities such as Tianjin . Hengshui, there also are a deep groundwater funnel.[6] Groundwater depletion is a direct threat to the safe water use in the cities of the plain in North China, which causes serious ground subsidence and sea water intrusion.

Table 4 The per capita share of water resources in different regions or periods

\begin{tabular}{cccccc}
\hline \multirow{2}{*}{ Partition } & \multicolumn{2}{c}{ Proportion of the whole country } & \multicolumn{3}{c}{$\begin{array}{c}\text { Per capita water } \\
\text { volume }\left(\mathrm{m}^{3}\right)\end{array}$} \\
& Water Resources & Population & 1997 & 2010 & 2050 \\
\hline $\begin{array}{c}\text { northeast } \\
\text { North }\end{array}$ & 7.0 & 9.6 & 1646 & 1501 & 1287 \\
$\begin{array}{c}\text { China } \\
\text { northwest }\end{array}$ & 7.7 & 34.7 & 500 & 449 & 389 \\
$\begin{array}{c}\text { south } \\
\text { whole }\end{array}$ & 4.8 & 2.1 & 4876 & 4140 & 3331 \\
country & 80.4 & 53.6 & 3481 & 2952 & 2634 \\
\hline
\end{tabular}

Economical Scarcity. Urban industrial water and has a direct relationship with and industrial scale and industrial industry. With the rapid development of economy, the scale of the industry is expanding, and the water demand is increasing. Beijing Tianjin Tangshan industrial zone has become the largest comprehensive industrial base in North china, a large number of industrial enterprises' establishment with large amount of water, such as the capital iron and steel industry, Yanshan Petrochemical industry, Tianjin Chemical Industry and so on, which makes the freshwater supply more nervous.

The lack of comprehensive utilization of water resources facilities lowers the comprehensive utilization of water resources. There is also a serious problem on pollution and waste.

North China water conservancy project, especially agricultural irrigation works is not matching and leakage, seepage control facilities is not perfect. Agricultural irrigation water seepage has different degree of agricultural irrigation water seepage, leakage phenomenon. Effective utilization of water resources is only about $50 \%$. Urban water supply loss rate is as high as more than $10 \%$ (including pipeline leakage).[7]

Sewage treatment rate is low, a large number of Living waste water, industrial waste water and Agricultural wastewater is discharged directly. Moreover, emissions of various wastes also contribute to the water pollution.

Other Aspects. Irrational use of water resources policy system, such as the price of water is too low, exacerbates the abuse of water. Besides natural environment influences, human exploiting over-usage and poor management are important factors that lead to water shortage

The Prediction of North China. Taking the the actual environmental conditions of North China into consideration, we optimize the ability model in the previous section to forecast the water situation in 15 years. The result is showed in the below figures. 


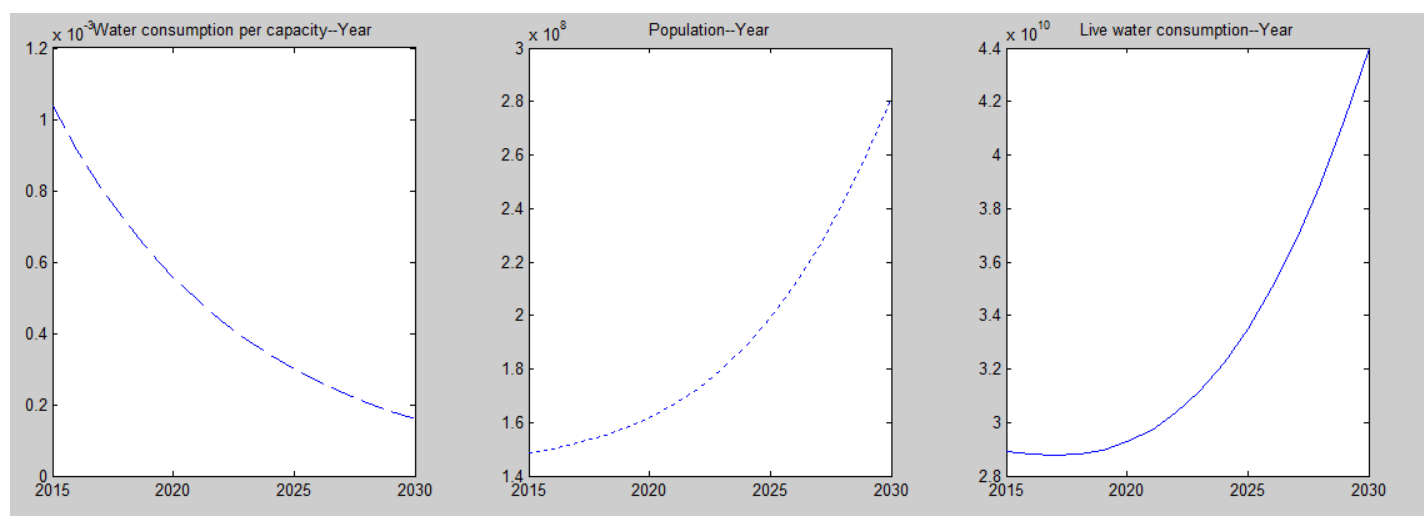

Figure 2. Live water consumption.
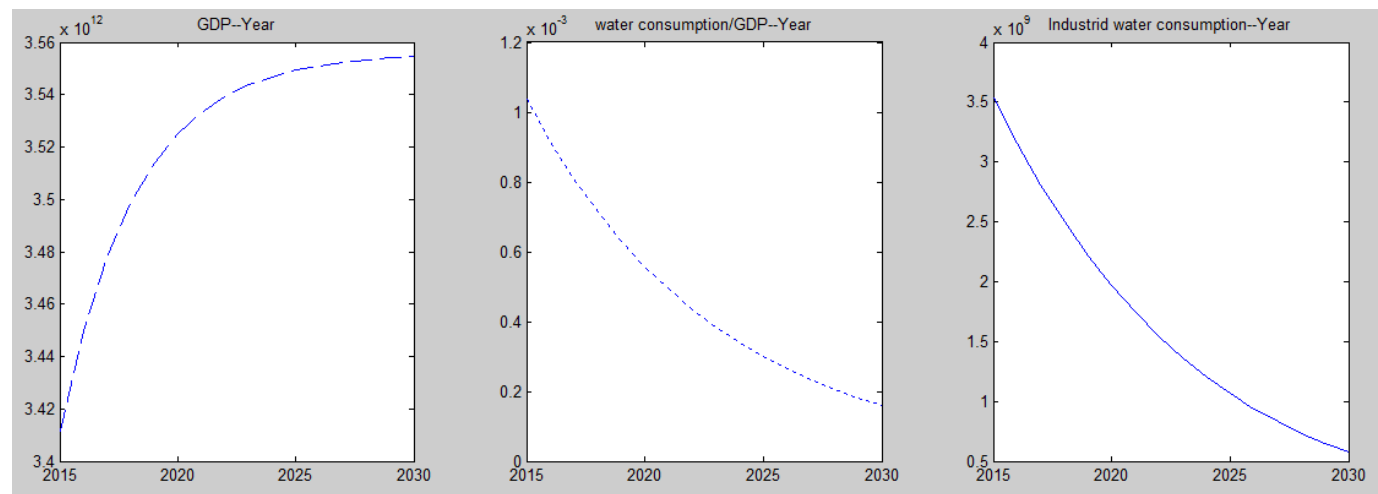

Figure 3. Industrial water consumption.

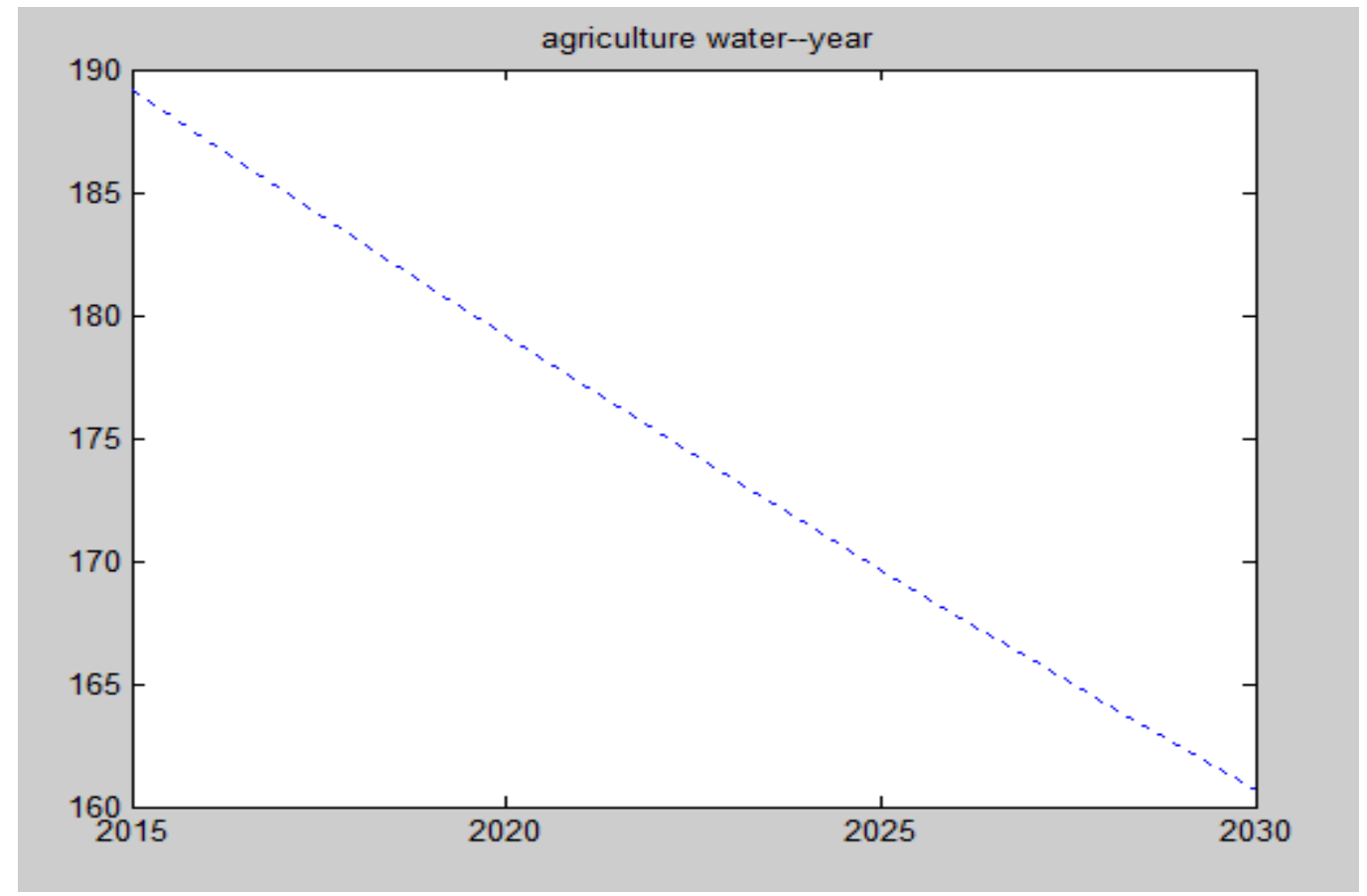

Figure 4. Agricultural water consumption. 


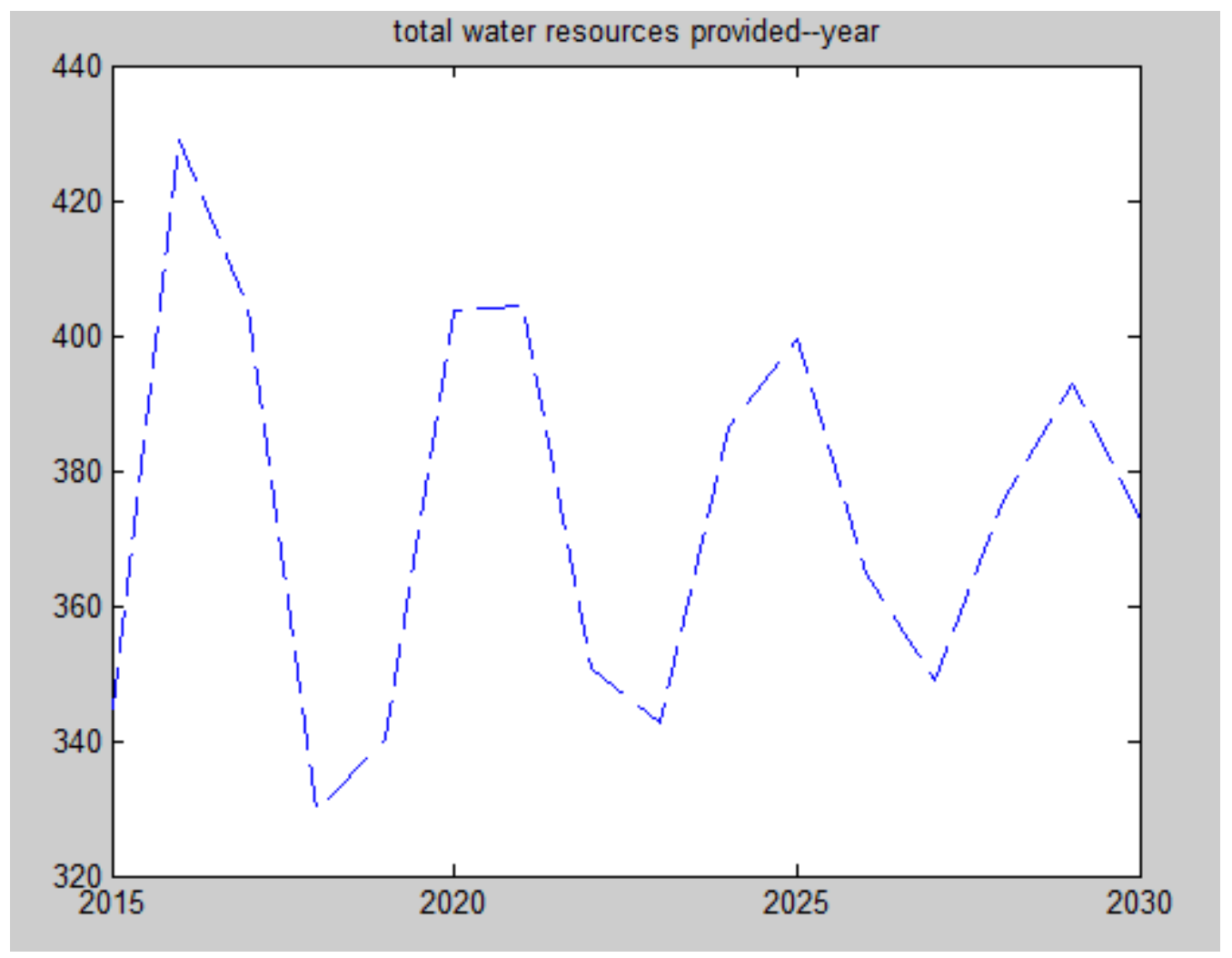

Figure 5. Total water resources provided

\section{The Forecast Result}

The water needed is 60.6286 billion cubic meters, available water is 37.27711 billion cubic meters in 2030. Water consumption is far more than provided, people will face more severe condition, which will affect people's life in many terms.

In agriculture, Grain output, plant withered death.

In industry, it will restrict the development of industry.

In daily life, the economic burden is heavier, the normal life is affected.

\section{The Intervention Plan}

From the analysis of the first water ability model, we can draw a conclusion that industrial water consumption Agricultural water accounts for a small proportion. So its effect is little. We mainly consider the water-saving plan on the terms of live water and agricultural water.

\section{Make Optimal Water Price}

In case that North China is starved of water. The development of water-saving plans is very important.

Water price is the main economic lever of water resources management, and plays an important role in guiding the allocation of water resources. Reasonable price can optimize the allocation of water resources, improve the use efficiency of water resources. Making scientific and reasonable price of water is the most effective measure to save water. The price of water in North China has a large deviation from the actual value of water. Low price of water has brought serious consequences. On the one hand, a direct result is lack the maintenance of water conservancy projects, update funds. On the other hand, users from all walks of life saving consciousness is very weak, further exacerbated the shortage of water resources situation.[8] 
We apply the Ramsey model[9] to make optimal water price.

\section{Ramsey Pricing Model}

\section{Assumption}

- People can accept the adjustment of water.

- Household water condition does not mutate suddenly.

Model Solution Progress. The cost of the water supply enterprise is approximately linear.

$T C=3 F+M C\left(Q_{L}+Q_{M}+Q_{H}\right)$

$F$ stands for the average fixed cost, which includes depreciation of plant and equipment, the water supply network laying and maintenance, technical personnel and management personnel wages and so on; $\mathrm{MC}$ for the marginal cost of per unit water, when the whole society need water in a range of changes, $\mathrm{MC}$ is a constant; $\mathrm{Q}$ stands for consumer water consumption[10]

The total income of water supply enterprises is:

$$
T R=Q_{L} P_{L}+\left[Q_{L} P_{L}+\left(Q_{M}-Q_{L}\right) P_{M}\right]+\left[Q_{L} P_{L}+\left(Q_{M}-Q_{L}\right) P_{M}+\left(Q_{H}-Q_{M}\right) P_{H}\right]=3 Q_{L} P_{L}+2\left(Q_{M}-Q_{L}\right) P_{M}+\left(Q_{H}-Q_{M}\right) P_{H}
$$

The total cost of the 3 products is TC. The water supply enterprise can set a minimum amount of profit for $\pi$

\section{$s t \sum_{i=1}^{a} Q_{i} P_{i}\left(Q_{i}\right)-T C \geq \pi$}

Make

$\pi=0$

The marginal social benefits for the production of more than one unit of production:

$$
S W_{i}\left(Q_{i}\right)=P_{i}\left(Q_{i}\right)-M C_{i}\left(Q_{i}\right)
$$

The objective function is the total social welfare SW (Social Welfare):

$$
S W=\sum_{i=1}^{m}\left[\int P_{i}\left(Q_{i}\right)-M C_{\bar{i}}\left(Q_{i}\right)\right] d Q_{i}
$$

Lagrange multiplier method is used to find the social welfare of the 3 products and maximize the production of Qi ( $\mathrm{i}=\mathrm{L}, \mathrm{M}, \mathrm{H})$ :

$$
\max L\left(Q_{i}, \lambda\right)=\sum\left[\int P_{i}\left(Q_{i}\right)-M C\right] d Q_{i}+\lambda\left[\sum Q_{i} P_{i}\left(Q_{i}\right)-T C-\pi\right]
$$

Order the first derivative is equal to 0 :

$$
\frac{\partial L}{\partial Q_{i}}=\left[P_{i}\left(Q_{i}\right)-M C_{i}\right]+\lambda\left[P_{i}\left(Q_{i}\right)+Q_{i} \frac{\partial P_{i}\left(Q_{i}\right)}{\partial Q_{i}}-M C_{i}\right]=0
$$

Then 


$$
\begin{aligned}
& \frac{P_{i}\left(Q_{i}\right)-M C}{P_{i}\left(Q_{i}\right)}=-\frac{l}{1+l} \mathrm{~g} \frac{1}{e_{i}} \\
& \frac{P_{i}^{*}\left(Q_{i}\right)-M C_{i}}{P_{i}^{*}\left(Q_{i}\right)}=-\frac{l}{1+l} \frac{\frac{d P_{i}^{*}\left(Q_{i}\right)}{P_{i}^{*}\left(Q_{i}\right)}}{\frac{d Q_{i}}{Q_{i}}}=-\frac{l}{1+l} \mathrm{~g} \frac{1}{e_{i}} \\
& e_{i}=\frac{\frac{d P_{i}^{*}\left(Q_{i}\right)}{P_{i}^{*}\left(Q_{i}\right)}}{\frac{d Q_{i}}{Q_{i}}}
\end{aligned}
$$

$\varepsilon_{i}$ is the price elasticity of Article I products

Assume

$$
\mathrm{D} P_{i}=\frac{P_{i}^{*}\left(Q_{i}\right)-M C_{i}}{P_{i}^{*}\left(Q_{i}\right)}
$$

The meet conditions

$$
e_{i} \mathrm{D} P_{i}=-\frac{l}{1+l}
$$

So for the ladder type price system in any of the two steps of the ladder $I$ and $j(1 \leq i \leq m, 1 \leq j \leq$ $\mathrm{m})$, Both of them meet the following equation

$\varepsilon_{i} \mathrm{~V} P_{i}=\varepsilon_{j} \mathrm{~V} P_{j}$

So

$$
P_{M}^{*}=\frac{M C}{1-\frac{e_{L}}{e_{M}} \frac{P_{L}^{*}-M C}{P_{L}^{*}}} \quad P_{H}^{*}=\frac{M C}{1-\frac{e_{L}}{e_{H}} \frac{P_{L}^{*}-M C}{P_{L}^{*}}}
$$

Therefore, the total income formula can be expressed as

$$
T R=3 Q_{L}^{*} P_{L}^{*}+2\left(Q_{M}^{*}-Q_{L}^{*}\right) \frac{M C}{1-\frac{e_{L}}{e_{M}} \frac{P_{L}^{*}-M C}{P_{L}^{*}}}+\left(Q_{H}^{*}-Q_{M}^{*}\right) \frac{M C}{1-\frac{e_{L}}{e_{H}} \frac{P_{L}^{*}-M C}{P_{L}^{*}}}=T C=3 F+M C\left(Q_{L}^{*}+Q_{M}^{*}+Q_{H}^{*}\right)
$$

Qi*and $\mathrm{Pi}^{*}$ meet the following relationship:

$$
\ln Q_{i}^{*}=C_{i}=\varepsilon_{i} \bullet \ln P_{i}^{*}(i=L, M, H)
$$

\section{Strength and Weakness}

Strength: By making the optimal water price to restrain the water consumption. Improve people's awareness of water conservation, save water to a certain extent.

Weakness: Widening the gap between the rich and the poor and some residents can not accept. 


\section{Change the Way of Irrigation}

\section{Assumption}

- Flood irrigation is the only irrigation method.

- All of the agricultural crops can be implemented by sprinkler irrigation.

Model. Equation of water consumption by sprinkler irrigation:

$$
W=\sum_{i}\left(p_{i} \bullet t_{i}\right) \bullet S \bullet c
$$

$W$ stands for water consumption.

$p$ stands for Percentage of crop coverage.

$t$ stands for Crop growth cycle.

$S$ stands for total cultivated land area.

$c$ stands for sprinkler irrigation water per cultivated area.

Strength and Weakness. Strength: Effectively save water, improve the utilization rate of water, more favorable to the plant.

Weakness: Not all land is suitable for the implementation of sprinkler irrigation.

The Forecast. Combined with the water price model mentioned above, we obtain that:

Average price of residents is 10.07 yuan. Per capita water consumption is $124.678 \mathrm{~m}^{3}$ per year.

We apply the Alternative Model to predict the future water consumption.

Because water has obvious irregularity and concentrated, so over the past 30 years, and forecast the next 25 years maximum 390 said years of water resources to maximize, minimum 362 said the minimum limit of water resources by solving the model, changes in the price of water while ignoring the proportion of small agricultural and industrial water, the North China area per capita water will be approaching a constant value $124.6782 \mathrm{~m} 3$ / year. According to the forecast, in 2137, the life of the water volume of over a billion cubic meters, while the total amount of water resources at this time predicted a value of 341.6923 .

\section{Conclusion}

In this paper, we manage to build a model to measure the water supply ability and forecast a region's water condition. And we can see that this model agrees well with the reality.

We analyze the reasons of water scarcity of North China. They are as follows:

The temporal and spatial distribution of water resources.

Over exploitation of underground water made a funnel structure formed.

Industrial and agricultural development, the demand is large.

Lack of comprehensive utilization of water resources facilities.

Unreasonable price of water.

Apart from the intervention plan we designed, there are some other suggestions.

Water resources storage,

Improve the quality of ecological environment

Strengthen the supervision and management system

Key shifts in industrial and agricultural production

\section{Strength and Weakness}

Strength. We simplify the model so that it is easy to understand and solving.

Our model is practical, and it turns out to be very good at tackling with practical situation.

Weakness. To simplify the problem, we ignore some factors.

Some assumptions in our model may nearly not be achieved at all. 


\section{References}

[1] World water resources status

[2] http://stuweb.zjhzyg.net/2006/_private/0810/081032/_private/shujie\%20.htm

[3] Environment Issues, Japan Fact Sheet, Retrieved February 4th,2013,from Web Japan

[4] ZHONG Chen-yu; HU Hui-ting; School of Mathematics \& Computational Science, Sun YatSen University, Based on grey prediction and multi-objective programming model of water prediction and optimal allocation, Journal of Sichuan University of Science \& Engineering(Natural Science Edition,2013.

[5] Chun Gong, Zhenglin Wang, 2009, Master Matlab Optimzied Calculation, pp 270-303,Beijing, Publishing House of Electronics Indstry.

[6] http://wenku.baidu.com/link?url=DHN3yFVgsSG1S.

[7] Wenxiu Zhang, The Current Situation and Prospect of Urban Water

[8] Resources in North China and Water Saving Measures, Shijiazhuang Vocational College of Law and Commerce Teaching and Research, 2005, 1(3),21-27.

[9] Guohong zhao, Make Reasonable Water Price and Promote Water Saving, Shandong Water Conservancy, 2001, (6).

[10] Xiaowei Ma, Study on Pricing Strategy of Increasing Block Tariffs, Science Technology and Engineering, 8(24), 6544-6552.

[11] Murat Kilic, Suer Anac. Multi-Objective Planning Model for Large Scale Irrigation Systems: Method and Application [J]. Water Resources Management. 2010 (12)

[12]Feng Shi, Xiaochuan Wang, Lei Yu, Yang Li, YangLiang Zhang,2010,MATLAB neural networks:30 case studies,pp21-35,Beijing:BUAA Press,7-5124-0034-4 